\title{
Growing interest in primary care research
}

$\mathrm{F}$ amily physicians' appetite for medical research that can improve their practices has "gone through the roof," says Dr. David White, deputy chair of family and community medicine at the University of Toronto.

At the recent Family Medicine Forum 2014, held in Quebec City on Nov. 13-15, White and Dr. David Kaplan, associate professor of family and community medicine at the University of Toronto, highlighted nine studies with the potential to impact clinical practice for family physicians.

Several years ago, when they first held this session at the annual conference, there was a modestly sized but engaged audience. It didn't take long, however, for interest to grow. So much so that one year the crowd was so large it was considered a fire hazard, and the session had to be relocated to a larger room.

There was a time when family doctors primarily looked to research conducted by specialists and tried to figure out if it could be applied to their practices. But it became apparent that there was a great need for research conducted in primary care settings by practitioners of the discipline, and the learning model has now shifted to one of peers learning from peers.

"It's a real revolution in family medicine," says White. "The quality of research has really gone up in primary care."

In choosing studies to present at the conference, White and Kaplan concentrated on research that can actually make a difference in clinical practice. They also focus on topical issues, such as opioid abuse and heart failure, that practising physicians deal with every day. Canadian context is also considered. A paper out of the United States, for example, might be interesting but too closely tied to funding or personnel issues specific to that country's health care system.

"It's not just that it has clinical relevance, it actually has to have wide

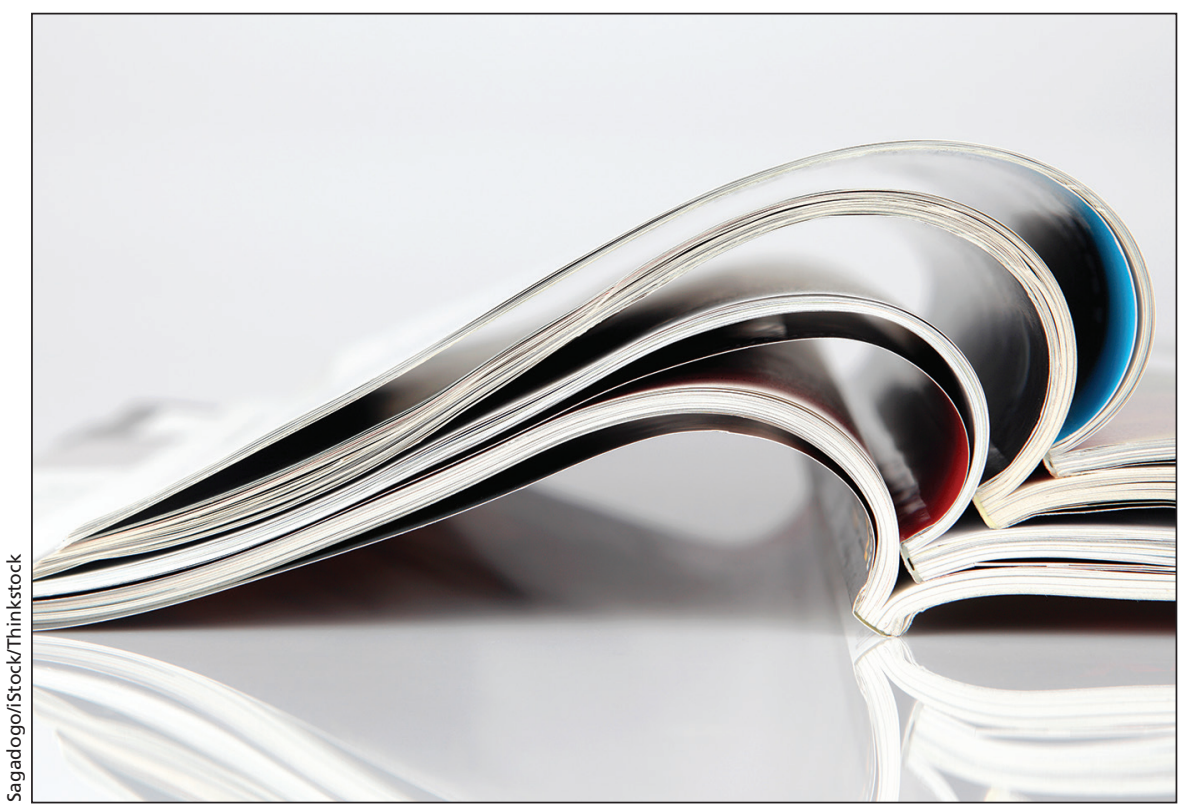

It is becoming more common to see primary care research in the pages of medical journals, though not all studies will have an impact on clinical practice.

clinical relevance," says Kaplan. "It's not some esoteric thing that you may see once a year. It is something you are seeing and dealing with all the time."

The search for relevant research will inevitably yield some studies with great potential to have immediate impact, says White, though there is no shortage of stinkers out there too. "With some things, you think, this belongs in the Journal of Irrelevant Results," he says.

Two studies that Kaplan found particularly interesting this year offered practical tools for family doctors. One was a systematic review of the validity and reliability of measuring capillary refill time to assess the severity of illness in children. This type of information could help a doctor determine if a sick child should be admitted to the emergency department or be sent home to rest.

"Giving clinicians another useful diagnostic tool to assess how unwell a child may be is something that people who come home from that session will have in the back of their minds, and the next time they see a sick kid, they are going to think about maybe checking capillary refill time," says Kaplan.
The other study explored the potential role of $\mathrm{N}$-terminal pro-B-type natriuretic peptide in screening for and predicting prognosis in heart failure. Canadian physicians are seeing many patients with heart failure being repeatedly admitted to hospital, says Kaplan. "One of the most difficult things to do with those patients and their families is to prognosticate and say where they are in this journey with this chronic disease."

Another relevant study, noted White, was one that looked at developing tools to help patients understand controversial cancer screening recommendations. Patients are bombarded with such information, some of it contradicting previous screening recommendations, and often look to their family doctors for guidance.

"[The study looked at how to] help people sort through those very nuanced recommendations where the evidence is conflicted," says White. "That is just the kind of thing that family doctors are grappling with all the time." - Roger Collier, CMAJ

CMAJ 2015. DOI:10.1503/cmaj.109-4946 